\title{
DIÁLOGO COM MARIA JOÃO CANTINHO \\ PARA QUE NÃO SE ESQUEÇA: FOTOGRAFIA E IMAGEM EM WALTER \\ BENJAMIN E GEORGES DIDI-HUBERMAN
}

Angelita Soares Ribeiro

Denise Marcos Bussoletti

\begin{abstract}
RESUMO
A filósofa portuguesa Maria João Cantinho é autora dos livros "O Anjo Melancólico: Ensaio sobre o conceito de alegoria na obra de Walter Benjamin", e "Walter Benjamin, Messianismo e Revolução: a história secreta: Ensaio sobre o Conceito de Messianismo na Obra de Walter Benjamin". O diálogo com Maria João Cantinho transcrito abaixo, ocorreu em dezembro de 2016, ocasião em que encerrávamos um período de estágio sanduíche no Centro de Filosofia da Faculdade de Letras da Universidade de Lisboa (Portugal) sob sua orientação. Percorrendo as concepções de fotografia e imagem na obra de Walter Benjamin em diálogo com Georges Didi-Huberman, a filósofa fala daquilo que ainda hoje podem as imagens enquanto ruptura do continuum da barbárie e retomada de promessas.
\end{abstract}

Palavras-Chave: Imagem dialética, Alegoria, História.

\section{DIALOGUE WITH MARIA JOÃO}

SO THAT YOU DON'T FORGET: PHOTOGRAPHY AND IMAGE IN WALTER BENJAMIN AND GEORGES DIDI-HUBERMAN

\begin{abstract}
The Portuguese philosopher Maria João Cantinho is the author of the books $O$ Anjo Melancólico: Ensaio sobre o conceito de alegoria na obra de Walter

Doutoranda em Educação e pesquisadora no Grupo Interdisciplinar de Pesquisa: Narrativas, Arte, Linguagem e Subjetividade (GIPNALS) junto ao Programa de Pós-graduação em Educação da Universidade Federal de Pelotas (PPGE/UFPel). Assistente Social e Coordenadora do Núcleo de Exensão e Pesquisa em Educação, Memória e Cultura (NEPEC) junto ao Campus Pelotas Visconde da Graça do Instituto Federal de Educação, Ciência e Tecnologia Sul-Rio-grandense (IFSul). Brasileira, residente em Rio Grande do Sul. Email: srangelita@hotmail.com

Doutora em Psicologia Social. Docente vinculada à Faculdade de Educação (FaE) da Universidade Federal de Pelotas e Coordenadora do Grupo Interdisciplinar de Pesquisa: Narrativas, Arte, Linguagem e Subjetividade (GIPNALS) junto ao Programa de Pós-graduação em Educação da Universidade Federal de Pelotas (PPGE/UFPel). Brasileira, residente em Rio Grande do Sul. Email: denisebussoletti@gmail.com
\end{abstract}


Benjamin", and "Walter Benjamin, Messianismo e Revolução: a história secreta: Ensaio sobre o Conceito de Messianismo na Obra de Walter Benjamin". The dialogue with Maria João Cantinho, transcribed below, took place in December 2016, when we concluded a period of sandwich training at the Centro de Filosofia of the Faculdade de Letras of Universidade de Lisboa (Portugal) under her guidance. Going through the conceptions of photography and image in the works of Walter Benjamin in dialogue with Georges Didi-Huberman, the philosopher speaks of what still today can the images as a rupture of the continuum of barbarism and resumption of promises.

Keys-Word: Dialectical image, Allegory, History.

\section{Apresentação}

Maria João Cantinho nasceu em 1963, em Lisboa/Portugal e viveu a sua infância em Angola. Em Fevereiro de 1975 regressa a Portugal, licenciando-se em Filosofia na Universidade Nova de Lisboa. Realizou na mesma instituição sua dissertação de mestrado, que culminou na publicação do livro "O Anjo Melancólico: Ensaio sobre o conceito de alegoria na obra de Walter Benjamin", e sua tese de doutorado, publicada sob o título "Walter Benjamin, Messianismo e Revolução: a história secreta: Ensaio sobre o Conceito de Messianismo na Obra de Walter Benjamin”. Atualmente é professora no Ensino Secundário, membro integrado do Centro de Filosofia da Faculdade de Letras de Lisboa, membro Associado do Collège d'Études Juives et de Philosophie Contemporaine, membro da Direcção do Pen Clube Português, da APE (Associação Portuguesa de Escritores) e da APCL (Associação Portuguesa de Críticos Literários). Além de suas obras acadêmicas, publicou várias obras de Ficção, Poesia e Ensaio.

Doutoranda em Educação e pesquisadora no Grupo Interdisciplinar de Pesquisa: Narrativas, Arte, Linguagem e Subjetividade (GIPNALS) junto ao Programa de Pós-graduação em Educação da Universidade Federal de Pelotas (PPGE/UFPel). Assistente Social e Coordenadora do Núcleo de Exensão e Pesquisa em Educação, Memória e Cultura (NEPEC) junto ao Campus Pelotas Visconde da Graça do Instituto Federal de Educação, Ciência e Tecnologia Sul-Rio-grandense (IFSul). Brasileira, residente em Rio Grande do Sul. Email: srangelita@hotmail.com

Doutora em Psicologia Social. Docente vinculada à Faculdade de Educação (FaE) da Universidade Federal de Pelotas e Coordenadora do Grupo Interdisciplinar de Pesquisa: Narrativas, Arte, Linguagem e Subjetividade (GIPNALS) junto ao Programa de Pós-graduação em Educação da Universidade Federal de Pelotas (PPGE/UFPel). Brasileira, residente em Rio Grande do Sul. Email: denisebussoletti@gmail.com 
O diálogo com Maria João Cantinho transcrito abaixo, ocorreu em dezembro de 2016, ocasião em que encerrávamos um período de três meses de estágio sanduíche no Centro de Filosofia da Faculdade de Letras da Universidade de Lisboa (Portugal) sob sua orientação. A tese, que nesse período foi co-orientada pela filósofa, vincula-se ao Programa de Pósgraduação em Educação (PPGE) da Universidade Federal de Pelotas (UFPel), e debruça-se sob centenas de fotografias que registram a passagem de meninos por uma escola agrícola do sul do Brasil, no inicio do século XX. Em anonimato, esses meninos eram chamados de "menores desvalidos". Tomando como referencial central a obra de Walter Benjamin em diálogo com Georges Didi-Huberman, a tese problematiza os modos pelos quais as fotografias podem operar enquanto imagens dialéticas que dobram o tempo (re)pactuam promessas.

\section{Introdução}

Em uma abordagem fisiognômica, Walter Benjamin realiza um exame minucioso de imagens prenhes de história. " [...] Ele atribui à fisiognomia das cidades, à cultura do cotidiano, às imagens do desejo e fantasmagorias, aos resíduos e materiais aparentemente insignificantes a mesma importância que às "grandes ideias" e às obras de arte consagradas" (BOLLE, 2000, 42-43).

Para Benjamin (2006, 518 [N11,2]) "Escrever a história significa dar às datas a sua fisiognomia", pois "[...] A história se decompõe em imagens, não em histórias" (BENJAMIN, 2006, 518 [N11,4]). Através do método da montagem utilizado no projeto das Passagens, Benjamin nos mostra uma "[...] arte de escrever a história através de imagens" (BUSSOLETTI, 2010, 01). O Doutoranda em Educação e pesquisadora no Grupo Interdisciplinar de Pesquisa: Narrativas, Arte, Linguagem e Subjetividade (GIPNALS) junto ao Programa de Pós-graduação em Educação da Universidade Federal de Pelotas (PPGE/UFPel). Assistente Social e Coordenadora do Núcleo de Exensão e Pesquisa em Educação, Memória e Cultura (NEPEC) junto ao Campus Pelotas Visconde da Graça do Instituto Federal de Educação, Ciência e Tecnologia Sul-Rio-grandense (IFSul). Brasileira, residente em Rio Grande do Sul. Email: srangelita@hotmail.com

Doutora em Psicologia Social. Docente vinculada à Faculdade de Educação (FaE) da Universidade Federal de Pelotas e Coordenadora do Grupo Interdisciplinar de Pesquisa: Narrativas, Arte, Linguagem e Subjetividade (GIPNALS) junto ao Programa de Pós-graduação em Educação da Universidade Federal de Pelotas (PPGE/UFPel). Brasileira, residente em Rio Grande do Sul. Email: denisebussoletti@gmail.com 
tempo de leitura da história a partir da imagem se faz para Benjamin (2006) em um tempo dialético, onde tudo aquilo que "foi" encontra reconhecimento no que ocorre "agora". É de tal reconhecimento que uma constelação histórica imagética se forma, dobrando o tempo e promovendo aberturas possíveis, onde um recontar como retorno e promessa se coloca em virtualidade.

Aproximar-se da obra de Walter Benjamin é assim assumir como perspectiva epistemológica um contínuo transitar entre palavras e imagens. Dito de outra forma, estudar a obra benjaminiana é assumir o desafio de um pensamento que se elabora e se escreve por e entre imagens. Ao citar Rudolf Borchardt, Benjamin (2006, 500 [N1,8]) assume o lado pedagógico do projeto das Passagens: "[...] Educar em nós o médium criador de imagens para um olhar estereoscópico e dimensional para a profundidade da sombras históricas[...]".

Torna-se perceptível, no entanto, a forma como a concepção benjaminiana de imagem ultrapassa a crítica elaborada pelo autor acerca da imagem fotográfica e cinematográfica na era da reprodutibilidade técnica (BENJAMIN, 2012), ainda que ali esteja presente. Imagem para Benjamin também ultrapassa os sentidos filosóficos clássicos do conceito de representação (Repräsentation), aproximando-se mais do conceito de apresentação ou exposição (Darstellung) trabalhado principalmente em sua obra sobre a Origem do Drama Barroco Alemão (Ursprung des deutschen Trauerspiel) (BENJAMIM, 1991). Da imagem alegórica à imagem dialética, da teoria da linguagem à teoria da história, a imagem está presente na obra benjaminiana, devendo ser apreendida dentro do movimento vertiginoso com que Benjamin formula e dá movimento aos fenômenos, conceitos e ideias (BENJAMIN, 1991).

Doutoranda em Educação e pesquisadora no Grupo Interdisciplinar de Pesquisa: Narrativas, Arte, Linguagem e Subjetividade (GIPNALS) junto ao Programa de Pós-graduação em Educação da Universidade Federal de Pelotas (PPGE/UFPel). Assistente Social e Coordenadora do Núcleo de Exensão e Pesquisa em Educação, Memória e Cultura (NEPEC) junto ao Campus Pelotas Visconde da Graça do Instituto Federal de Educação, Ciência e Tecnologia Sul-Rio-grandense (IFSul). Brasileira, residente em Rio Grande do Sul. Email: srangelita@hotmail.com

Doutora em Psicologia Social. Docente vinculada à Faculdade de Educação (FaE) da Universidade Federal de Pelotas e Coordenadora do Grupo Interdisciplinar de Pesquisa: Narrativas, Arte, Linguagem e Subjetividade (GIPNALS) junto ao Programa de Pós-graduação em Educação da Universidade Federal de Pelotas (PPGE/UFPel). Brasileira, residente em Rio Grande do Sul. Email: denisebussoletti@gmail.com 
Pierre Missac $(1998,39)$ sugere que Walter Benjamin seja abordado de modo indireto, "[...] valendo-se quase de um artifício ou talvez meio sem querer, 'de passagem', seguindo o método que Ihe permitira fazer seus melhores achados de colecionador". Diante à densa e complexa teia de significados que elaboram a concepção de imagem na obra benjaminiana, aceitamos aqui a sugestão de Missac $(1998,28)$, extraindo dos textos de Benjamin "[...] momentos fugazes, reconhecendo-se neles[...]", agarrando "[...] no ar a ideia, a imagem ou a frase para depois voltar a cerrar os dedos sobre as costas do rosário laico e dar-Ihe uma forma nova".

O diálogo com Maria João Cantinho transcrito abaixo, deverá assim operar nesse movimento. Ou seja, na captura de achados, visitando sentidos na forma que se torna possível agarrá-los em sua passagem, na aproximação de conceitos que a primeira vista parecem divergir, e na aproximação de autores de tempos e lugares distintos. Este é o gesto que deverá promover aqui a elaboração do conceito de imagem enquanto lugar de memória e promessa a partir do encontro da obra de Walter Benjamin com a de Georges Didi-Huberman, um de seus principais comentadores e um dos mais importantes pensadores contemporâneos no que diz respeito a uma concepção do tempo no centro da imagem e da imagem no centro do tempo.

A noção de imagem se coloca de forma central na obra de Walter Benjamin. Ao mesmo tempo, a fotografia também foi geradora de profícuas problematizações

Doutoranda em Educação e pesquisadora no Grupo Interdisciplinar de Pesquisa: Narrativas, Arte, Linguagem e Subjetividade (GIPNALS) junto ao Programa de Pós-graduação em Educação da Universidade Federal de Pelotas (PPGE/UFPel). Assistente Social e Coordenadora do Núcleo de Exensão e Pesquisa em Educação, Memória e Cultura (NEPEC) junto ao Campus Pelotas Visconde da Graça do Instituto Federal de Educação, Ciência e Tecnologia Sul-Rio-grandense (IFSul). Brasileira, residente em Rio Grande do Sul. Email: srangelita@hotmail.com

Doutora em Psicologia Social. Docente vinculada à Faculdade de Educação (FaE) da Universidade Federal de Pelotas e Coordenadora do Grupo Interdisciplinar de Pesquisa: Narrativas, Arte, Linguagem e Subjetividade (GIPNALS) junto ao Programa de Pós-graduação em Educação da Universidade Federal de Pelotas (PPGE/UFPel). Brasileira, residente em Rio Grande do Sul. Email: denisebussoletti@gmail.com 
benjaminianas. É possível uma aproximação entre a concepção de imagem e a análise crítica da fotografia, ambas elaboradas pelo autor ${ }^{1}$ ?

Quando Walter Benjamin fala na fotografia, ele está falando da imagem alegórica. E imagem alegórica é imagem coagulada, é da imagem petrificada que ele está a falar. Tanto que ele diz que as únicas imagens da fotografia que mantêm a aura são aquelas que têm um caráter que pode ser considerado simbólico, são as fotografias onde se encontra o rosto. As outras estão esvaziadas da figura humana. Comparável àquele texto que ele fala do cunho humano, dos objetos que são fabricados pelo cunho humano, e os objetos que são fabricados pela máquina.

Portanto, o que eu quero dizer com isso é que esta relação da imagem à crítica da fotografia tem que ver com o próprio procedimento alegórico. Ou seja, quando Benjamin faz a crítica à fotografia, ele tem sempre presente o contexto da imagem alegórica. E esta é uma imagem no qual já entrou em declínio a aura, ou seja, o cunho, a marca do humano está a desaparecer. Por isto é que ele cita como grande fotógrafo da época o Atget, que leva isto ao clímax ao esvaziar as ruas de Paris. Aquelas imagens fotográficas de Atget, são imagens alegóricas. Isso é o espírito da época no sentido do esvaziamento do humano, da marca, do cunho. Enquanto que a imagem que conserva mais a aura é aquela imagem que o burguês leva para dentro de casa, a fotografia de um familiar ou de um amigo porque ele ainda quer registrar a presença do humano. Mas esta não é a imagem alegórica.

\footnotetext{
${ }^{1}$ BENJAMIN, 1991; 2006; 2012.

Doutoranda em Educação e pesquisadora no Grupo Interdisciplinar de Pesquisa: Narrativas, Arte, Linguagem e Subjetividade (GIPNALS) junto ao Programa de Pós-graduação em Educação da Universidade Federal de Pelotas (PPGE/UFPel). Assistente Social e Coordenadora do Núcleo de Exensão e Pesquisa em Educação, Memória e Cultura (NEPEC) junto ao Campus Pelotas Visconde da Graça do Instituto Federal de Educação, Ciência e Tecnologia Sul-Rio-grandense (IFSul). Brasileira, residente em Rio Grande do Sul. Email: srangelita@hotmail.com

Doutora em Psicologia Social. Docente vinculada à Faculdade de Educação (FaE) da Universidade Federal de Pelotas e Coordenadora do Grupo Interdisciplinar de Pesquisa: Narrativas, Arte, Linguagem e Subjetividade (GIPNALS) junto ao Programa de Pós-graduação em Educação da Universidade Federal de Pelotas (PPGE/UFPel). Brasileira, residente em Rio Grande do Sul. Email: denisebussoletti@gmail.com
} 
Mas, em síntese, a imagem que Benjamin está a falar na critica à fotografia é a imagem alegórica, este modus operandi que será a própria experiência de choque da modernidade, referindo-se sobretudo às imagens de Atget.

Seria possível pensar a noção benjaminiana de imagem dialética também através da fotografia?

Nós estamos falando de planos diferentes, não é? A imagem dialética é a possibilidade da leitura da história. A imagem da fotografia é a da captação sem leitura, imediata. É uma espécie de colagem. Legenda e imagem, como Benjamin define a alegoria. Enquanto que a imagem dialética é abertura para a possibilidade de leitura da história. Ou seja, a imagem dialética fixa, no sentido da petrificação do instante dialético, mas concentra em si o passado (o que Benjamin chama de outrora) e o presente. Ou seja, é como se a imagem dialética tivesse uma dobra onde tu encontras ainda uma possibilidade de leitura, de abertura. Não é a imagem da fotografia. A imagem da fotografia é alegórica.

Portanto, se é possível a partir da fotografia pensarmos a imagem dialética, eu penso que esta relação pode ser forçada. Ao mesmo tempo, é evidente que Benjamin considera a questão do arquivo, ainda que não trabalhe esse tema, mas, sobretudo o da colecção. Apesar de ele não falar no livro das Passagens sobre o arquivo, sobre os documentos, há um momento em que fala do vestígio, do traço. E aí, talvez, fazendo esta leitura, pensando a fotografia como um traço, isto permita-nos reenviá-la para a imagem dialética. Ou seja, a imagem fotográfica como vestígio. Porque a fotografia como Doutoranda em Educação e pesquisadora no Grupo Interdisciplinar de Pesquisa: Narrativas, Arte, Linguagem e Subjetividade (GIPNALS) junto ao Programa de Pós-graduação em Educação da Universidade Federal de Pelotas (PPGE/UFPel). Assistente Social e Coordenadora do Núcleo de Exensão e Pesquisa em Educação, Memória e Cultura (NEPEC) junto ao Campus Pelotas Visconde da Graça do Instituto Federal de Educação, Ciência e Tecnologia Sul-Rio-grandense (IFSul). Brasileira, residente em Rio Grande do Sul. Email: srangelita@hotmail.com

Doutora em Psicologia Social. Docente vinculada à Faculdade de Educação (FaE) da Universidade Federal de Pelotas e Coordenadora do Grupo Interdisciplinar de Pesquisa: Narrativas, Arte, Linguagem e Subjetividade (GIPNALS) junto ao Programa de Pós-graduação em Educação da Universidade Federal de Pelotas (PPGE/UFPel). Brasileira, residente em Rio Grande do Sul. Email: denisebussoletti@gmail.com 
documento permite esta abertura para a leitura do vestígio, daqueles que ficaram nesta fotografia. Não é? Penso que é possível... Neste sentido, esta leitura é possível.

Porque neste sentido não é uma leitura crítica no sentido estético que Benjamin está a fazer na critica à obra de arte, mas é a leitura histórica da fotografia, e ela pode funcionar desta forma, ou seja, como leitura e interpretação do passado.

Estaríamos então falando da fotografia como um acesso à imagem dialética? Ou como uma imagem dialética em si?

Neste caso a fotografia pode ser tomada como uma imagem dialética, porque permite esse acesso, permite que possamos prosseguir até à investigação daqueles que aí estiveram, como leitura da história desses vencidos que lá estiveram. Porque, a partir destas fotografias, podes ter acesso ao vivo. São coisas mortas, são imagens mortas, mas pelas quais se é possível ter acesso ao vivo.

Esta perspectiva de leitura tem alguma relação com aquilo que George DidiHuberman vai tratar no livro "Images malgré tout"?

Sim. Tem porque Didi-Huberman, nesse livro, faz a análise das experiências do horror, do holocausto, sobretudo de Auschwitz. E trabalha

\footnotetext{
2 DIDI-HUBERMAN, 2003.
}

Doutoranda em Educação e pesquisadora no Grupo Interdisciplinar de Pesquisa: Narrativas, Arte, Linguagem e Subjetividade (GIPNALS) junto ao Programa de Pós-graduação em Educação da Universidade Federal de Pelotas (PPGE/UFPel). Assistente Social e Coordenadora do Núcleo de Exensão e Pesquisa em Educação, Memória e Cultura (NEPEC) junto ao Campus Pelotas Visconde da Graça do Instituto Federal de Educação, Ciência e Tecnologia Sul-Rio-grandense (IFSul). Brasileira, residente em Rio Grande do Sul. Email: srangelita@hotmail.com

Doutora em Psicologia Social. Docente vinculada à Faculdade de Educação (FaE) da Universidade Federal de Pelotas e Coordenadora do Grupo Interdisciplinar de Pesquisa: Narrativas, Arte, Linguagem e Subjetividade (GIPNALS) junto ao Programa de Pós-graduação em Educação da Universidade Federal de Pelotas (PPGE/UFPel). Brasileira, residente em Rio Grande do Sul. Email: denisebussoletti@gmail.com 
sobre a questão da memória de uma forma mais complexa que o próprio Benjamin o faz, amplia as teses de Benjamin.

Como se sabe, Didi-Huberman é um comentador do Benjamin, mas expande esta leitura através do Aby Warburg. E também, através dele próprio, porque o que há de Aby Warburg em Didi-Huberman é discutível, pois ele vai muito além. Portanto, ele é um herdeiro de Warburg. O que eu quero dizer com isso é que aquela ideia que ele tem da imagem do holocausto é como memória sobrevivente. São conceitos que podem reconhecer-se na concepção benjaminiana da imagem dialética, e há um estudo sobre isso, aliás, eu tenho um estudo ${ }^{3}$ sobre isso em que faço essa passagem do que é imagem sobrevivente, dos fantasmas, da vida póstuma das imagens, o nachleben, que tem precisamente a ver com isso: As imagens retornam. Ao mesmo tempo são memórias e, enquanto memória tem alojada em si o futuro, e essa possibilidade da leitura que se abre ao presente e ao porvir.

Portanto, quando se fala da sobrevivência das imagens tem que ver ao mesmo tempo com essa capacidade de leitura do passado, mas também da apreciação do potencial que estas imagens têm para poderem ser lidas no futuro. Essa sobrevivência não se esgota no presente. Ela é presente, é passado, mas não esgota nisso. Abre para uma outra dimensão, a do porvir. Quando falo do porvir, tento não utilizar a expressão do futuro, porque sabem que o pensamento judeu «lidava mal» com a ideia do futuro. Podem ler isso na última tese do livro de Benjamin, «Sobre o Conceito de História» ${ }^{4}$. Fala mais do

3 CANTINHO, Maria João. Aby Warburg e Walter Benjamin: a legibilidade da memória.Disponível

file:///C:/Users/Usuario/Downloads/Aby Warburg e Walter Benjamin A Legibili.pdf, acessado em 30/07/2016.

${ }^{4}$ BENJAMIN, 2012b.

Doutoranda em Educação e pesquisadora no Grupo Interdisciplinar de Pesquisa: Narrativas, Arte, Linguagem e Subjetividade (GIPNALS) junto ao Programa de Pós-graduação em Educação da Universidade Federal de Pelotas (PPGE/UFPel). Assistente Social e Coordenadora do Núcleo de Exensão e Pesquisa em Educação, Memória e Cultura (NEPEC) junto ao Campus Pelotas Visconde da Graça do Instituto Federal de Educação, Ciência e Tecnologia Sul-Rio-grandense (IFSul). Brasileira, residente em Rio Grande do Sul. Email: srangelita@hotmail.com

Doutora em Psicologia Social. Docente vinculada à Faculdade de Educação (FaE) da Universidade Federal de Pelotas e Coordenadora do Grupo Interdisciplinar de Pesquisa: Narrativas, Arte, Linguagem e Subjetividade (GIPNALS) junto ao Programa de Pós-graduação em Educação da Universidade Federal de Pelotas (PPGE/UFPel). Brasileira, residente em Rio Grande do Sul. Email: denisebussoletti@gmail.com 
porvir, do que propriamente do futuro. Do que há de vir. As imagens sobreviventes são abertas e restauradoras nesse sentido. É aberta porque abre para esta potencialidade, e ao mesmo tempo permite a restauração do passado.

Eu gosto de falar sempre na questão da dobra, como aquilo que permite a abertura e a salvação simultânea. É ao mesmo tempo um gesto de rememoração, mas é também um gesto de abertura. A rememoração num sentido proustiano, num sentido que não é apenas cronológico, da fixação da memória, mas a seleção daquilo que é importante rememorar. E as imagens do holocausto não tratam somente da questão cronológica, não se trata apenas do fato em si, do fato cronológico, mas a própria experiência que é resgatada ali. $E$ como experiência há uma dimensão subjetiva, que escapa à história neste sentido clássico e cronológico.

A rememoração contém esta dimensão subjetiva, que é a possibilidade de escolher e selecionar e resgatar a organicidade da experiência. A história cronológica só nos permite situar o fato, mas não nos permite resgatar a experiência.

Para problematizar um pouco mais ainda sobre a relação da imagem com a fotografia, neste livro especificamente, "Images malgré tout”, Didi-Huberman está pensando a questão da sobrevivência das imagens especificamente a partir das fotografias?

Exatamente, vamos imaginar uma coisa... Quando Benjamin escreveu o livro das Passagens e falava da imagem dialética, é evidente que a fotografia tinha um papel importante, mas não tínhamos passado pelo holocausto. Vamos

Doutoranda em Educação e pesquisadora no Grupo Interdisciplinar de Pesquisa: Narrativas, Arte, Linguagem e Subjetividade (GIPNALS) junto ao Programa de Pós-graduação em Educação da Universidade Federal de Pelotas (PPGE/UFPel). Assistente Social e Coordenadora do Núcleo de Exensão e Pesquisa em Educação, Memória e Cultura (NEPEC) junto ao Campus Pelotas Visconde da Graça do Instituto Federal de Educação, Ciência e Tecnologia Sul-Rio-grandense (IFSul). Brasileira, residente em Rio Grande do Sul. Email: srangelita@hotmail.com

Doutora em Psicologia Social. Docente vinculada à Faculdade de Educação (FaE) da Universidade Federal de Pelotas e Coordenadora do Grupo Interdisciplinar de Pesquisa: Narrativas, Arte, Linguagem e Subjetividade (GIPNALS) junto ao Programa de Pós-graduação em Educação da Universidade Federal de Pelotas (PPGE/UFPel). Brasileira, residente em Rio Grande do Sul. Email: denisebussoletti@gmail.com 
imaginar o que teria feito Benjamin com os conceitos depois do holocausto. Teria partido da experiência da fotografia? Penso que o Didi-Huberman fez exatamente o gesto que ele gostaria de ter feito, sem nada de sentimental no que estou dizendo. Estou a querer realmente pensar no que ele teria feito. Não estaria a lidar com o cinema e com as imagens como estamos a lidar hoje? Como o Didi-Huberman lida com essas imagens. Percebem? Eu acho que seria um gesto possível dele. Um gesto de rememoração, no qual ele se reconheceria. Ou seja, nesta ideia de vida póstuma das imagens, na ideia da rememoração, na ideia de não esquecer, que é uma coisa importante, do imperativo: "Não esquecer!".

Por isso, acredito que, se Walter Benjamin fosse vivo, ele teria provavelmente o mesmo gesto do Didi-Huberman, escrever a partir das imagens do holocausto. Escrever a partir daquilo que não pode ser esquecido. Escrever a partir dos vencidos da história, no caso estes das imagens do holocausto. Como no caso da tua pesquisa também, escrever a partir das imagens dos meninos. São gestos que estão associados à leitura da imagem dialética.

Além de falar sobre uma complexa dialética do olhar operada pelo "paradigma visual aurático", e do processo de abertura, fechamento, desaparição e sobrevivência das imagens, Didi- Huberman (2013, 193), ainda fala da imagem rasgadura, enquanto aquela noção de imagem que rasga radicalmente 0 conceito clássico de representação: "Uma função rasgada- isto é, que inclui a potência do negativo nela- preside assim, enquanto trabalho, à intensa ou evanescente visualidade das imagens no sonho". Diante a isso: É possível uma

Doutoranda em Educação e pesquisadora no Grupo Interdisciplinar de Pesquisa: Narrativas, Arte, Linguagem e Subjetividade (GIPNALS) junto ao Programa de Pós-graduação em Educação da Universidade Federal de Pelotas (PPGE/UFPel). Assistente Social e Coordenadora do Núcleo de Exensão e Pesquisa em Educação, Memória e Cultura (NEPEC) junto ao Campus Pelotas Visconde da Graça do Instituto Federal de Educação, Ciência e Tecnologia Sul-Rio-grandense (IFSul). Brasileira, residente em Rio Grande do Sul. Email: srangelita@hotmail.com

Doutora em Psicologia Social. Docente vinculada à Faculdade de Educação (FaE) da Universidade Federal de Pelotas e Coordenadora do Grupo Interdisciplinar de Pesquisa: Narrativas, Arte, Linguagem e Subjetividade (GIPNALS) junto ao Programa de Pós-graduação em Educação da Universidade Federal de Pelotas (PPGE/UFPel). Brasileira, residente em Rio Grande do Sul. Email: denisebussoletti@gmail.com 
noção de imagem em Didi-Huberman que transversalize todas estas abordagens do olhar (e do ser olhado) e da imagem ${ }^{5}$ ?

Acho que se cruzam aqui vários níveis. A ideia da aura, a ideia de algo, que Benjamin afirmava no livro das Passagens, que era a necessidade de criar uma história figurativa, que seria uma história construída a partir das imagens dialéticas, e, portanto, seria a procura de um novo paradigma para a compreensão da história.

E eu penso que Didi-Huberman procura fazer exatamente isso. Ele situa toda sua teoria, precisamente a partir da leitura da história da arte e das artes, a partir deste novo paradigma que Walter Benjamin pretende ter criado. E de fato, eu também acredito nisso. Quero dizer, há um novo paradigma. Depois de Warburg, depois dos estudos de Panofsky, depois dos estudos de Benjamin, não é possível olhar para a história da arte da mesma forma. Como também não é possível olhar para a própria história da mesma forma. Seriamos ingênuos se pensássemos: "Sim, eles escreveram estes textos e agora vamos continuar a história do progresso, na questão da linearidade como se nada fosse".

Mas o certo é que o Bloch nos anos 50 começou a defender conceitos como a imagem síncrona, no lugar da diacronia. Ou seja, nos anos 1950, o próprio Bloch já não acreditava nesta ideia da história como progresso, no sentido cronológico. Aliás, ele tentou resgatar a experiência dos vencidos, sem estar próximo da experiência benjaminina. É natural que Bloch tenha lido Benjamin e tenha despertado para esta dimensão da história que ainda não era

5 DIDI-HUBERMAN, 2003; 2007; 2010; 2013; 2013a; 2015.

Doutoranda em Educação e pesquisadora no Grupo Interdisciplinar de Pesquisa: Narrativas, Arte, Linguagem e Subjetividade (GIPNALS) junto ao Programa de Pós-graduação em Educação da Universidade Federal de Pelotas (PPGE/UFPel). Assistente Social e Coordenadora do Núcleo de Exensão e Pesquisa em Educação, Memória e Cultura (NEPEC) junto ao Campus Pelotas Visconde da Graça do Instituto Federal de Educação, Ciência e Tecnologia Sul-Rio-grandense (IFSul). Brasileira, residente em Rio Grande do Sul. Email: srangelita@hotmail.com

Doutora em Psicologia Social. Docente vinculada à Faculdade de Educação (FaE) da Universidade Federal de Pelotas e Coordenadora do Grupo Interdisciplinar de Pesquisa: Narrativas, Arte, Linguagem e Subjetividade (GIPNALS) junto ao Programa de Pós-graduação em Educação da Universidade Federal de Pelotas (PPGE/UFPel). Brasileira, residente em Rio Grande do Sul. Email: denisebussoletti@gmail.com 
contemplada. Porque a história é sempre a história dos poderosos, na relação com os poderosos. E o Bloch escreveu várias coisas sobre as mulheres, sobre aqueles que não apareciam na história, que não eram contemplados. Isso significa que, na mesma época, havia mais pessoas a pensar da mesma forma. Não era só Benjamin.

O que permite dizer que Didi-Huberman é um seguidor, não sei se podemos falar de uma nova escola, porque eu não acredito muito que exista... Quer dizer, no Brasil eu acredito que exista algo como uma escola do pensamento benjaminiano, na Europa não tanto. Creio que o Benjamin aqui em Portugal, não fez escola. Talvez na Teoria da Literatura, mas na história não. Creio que não há ninguém na história a trabalhar as teses de Benjamin. No Brasil sim. Acho que os leitores aí estão atentos. Há pessoas que trabalham com as teses dele. Isso significa que Didi-Huberman vai implantar na história da arte, também é uma leitura que está muito a ser feita no Brasil na história da arte a partir do próprio Didi-Huberman... Ou seja, curiosamente, ele é alguém que vai resgatar a experiência de Warburg, e acaba tendo mais peso na transformação do paradigma do que o próprio Benjamin. Porque há nas teses de Benjamin... Não sei se percebem, mas a transversalidade é isso, ou seja, uma espécie de herança que se afirma no herdeiro, não é? É o herdeiro que impõe o novo paradigma. E hoje em dia, quer se queira, quer não, ignorar 0 Didi-Huberman na história da arte é uma falácia. Inclusive os próprios conceitos que ele introduz, como os conceitos que já são warburguianos, como a ideia do nachleben, da vida póstuma das imagens, da questão da sobrevivência das imagens, a forma como ele trabalha a aura também. Tudo isso ele vai buscar também no próprio Benjamin.

Doutoranda em Educação e pesquisadora no Grupo Interdisciplinar de Pesquisa: Narrativas, Arte, Linguagem e Subjetividade (GIPNALS) junto ao Programa de Pós-graduação em Educação da Universidade Federal de Pelotas (PPGE/UFPel). Assistente Social e Coordenadora do Núcleo de Exensão e Pesquisa em Educação, Memória e Cultura (NEPEC) junto ao Campus Pelotas Visconde da Graça do Instituto Federal de Educação, Ciência e Tecnologia Sul-Rio-grandense (IFSul). Brasileira, residente em Rio Grande do Sul. Email: srangelita@hotmail.com

Doutora em Psicologia Social. Docente vinculada à Faculdade de Educação (FaE) da Universidade Federal de Pelotas e Coordenadora do Grupo Interdisciplinar de Pesquisa: Narrativas, Arte, Linguagem e Subjetividade (GIPNALS) junto ao Programa de Pós-graduação em Educação da Universidade Federal de Pelotas (PPGE/UFPel). Brasileira, residente em Rio Grande do Sul. Email: denisebussoletti@gmail.com 
Benjamin foi muito mais conhecido que o Aby Warburg, que caiu no esquecimento. Em certa altura, Walter Benjamin era uma figura intelectual muito séria, mas muito "apagada" em relação a Warburg. Havia um círculo do Warburg no qual Benjamin tentou entrar e foi, de certa forma, sempre afastado. Isso transparece na correspondência dele. $E$ depois, ele próprio abandonou esta ideia de se aproximar do Warburg, pois entendeu que não valia a pena por várias razões, até por causa da questão da fortuna.

Warburg era um homem muito rico, muito influente e Benjamin não, estando, portanto sempre à margem deste grupo. O que é interessante é que Warburg cai no esquecimento e o Benjamin é recuperado após o "Maio de 1968" em Paris. E é através de Benjamin que Warburg será recuperado. Isto é mesmo muito interessante. Ou seja, por que Benjamin teria procurado Warburg? Porque ele se reconheceu nas teses de Warburg. Pelo menos em algumas questões, como a própria leitura que ele fazia da história da arte, na questão da biblioteca, na questão do colecionador. Então, eles tinham um pensamento que era muito comum neste sentido. E que Warburg olhou desdenhosamente. Mas foi Walter Benjamin que permitiu a recuperação de Warburg, é preciso que isso seja dito. E Didi-Huberman teve um olhar muito atento, porque como historiador da arte e comentador de Benjamin soube compreender esta pertinência, essa transversalidade que existe entre ambos.

Para finalizar, retornamos ao que Didi-Huberman elabora como um paradigma aurático ${ }^{6}$, onde as imagens que olhamos também nos olham desde uma distância colocada como perda, como sintoma. Didi-Huberman em certo

\footnotetext{
6 DIDI-HUBERMAN, 2010.
}

Doutoranda em Educação e pesquisadora no Grupo Interdisciplinar de Pesquisa: Narrativas, Arte, Linguagem e Subjetividade (GIPNALS) junto ao Programa de Pós-graduação em Educação da Universidade Federal de Pelotas (PPGE/UFPel). Assistente Social e Coordenadora do Núcleo de Exensão e Pesquisa em Educação, Memória e Cultura (NEPEC) junto ao Campus Pelotas Visconde da Graça do Instituto Federal de Educação, Ciência e Tecnologia Sul-Rio-grandense (IFSul). Brasileira, residente em Rio Grande do Sul. Email: srangelita@hotmail.com

Doutora em Psicologia Social. Docente vinculada à Faculdade de Educação (FaE) da Universidade Federal de Pelotas e Coordenadora do Grupo Interdisciplinar de Pesquisa: Narrativas, Arte, Linguagem e Subjetividade (GIPNALS) junto ao Programa de Pós-graduação em Educação da Universidade Federal de Pelotas (PPGE/UFPel). Brasileira, residente em Rio Grande do Sul. Email: denisebussoletti@gmail.com 
momento parece dotar todas as imagens deste poder de distância, cabendo ao observador (e observado) apreendê-la. Mas, se pensarmos no contexto das imagens que surgem enquanto reprodutibilidade técnica, elas ainda podem nos olhar?

As imagens mecânicas não podem olhar-nos. Eu tenho as minhas dúvidas, mas quando Didi-Huberman faz a leitura da imagem, ele está presente num contexto da imagem que nos olha. Ou seja, a imagem é aquilo no qual nós mergulhamos e no qual nos podemos perder. Portanto temos que manter esta distância, para poder olhar para ela. Mas ela também tem que nos olhar para que possamos reconhecer-nos nela. E creio que estas imagens frenéticas não tem essa função de abertura. Mas isso tem que ver também com uma crítica que eu tenho em relação à arte. $E$ também não sei suficiente de arte contemporânea para poder responder-te a isso.

Mas por que há imagens que me falam e há outras que não me falam? Quando Didi-Huberman fala sobre a imagem ela quase sempre surge associada à ideia do arquivo, não é uma imagem qualquer. Que ela rasga com o tecido da representação sim, porque não é mimética. Ela não tem a função de reproduzir, pois obriga-nos a olhar para ela com esta distância crítica, que não pode ser nem demasiado perto, nem demasiado longe. Isto é muito interessante. É a distância do crítico, falava também Benjamin, nas Imagens do Pensamento 7 . O crítico tem que olhar a imagem numa determinada medida. $\mathrm{O}$ Didi-Huberman tem essa ideia também. Uma medida que não é mimética, mas

\footnotetext{
7 BENJAMIN, 2013.
}

Doutoranda em Educação e pesquisadora no Grupo Interdisciplinar de Pesquisa: Narrativas, Arte, Linguagem e Subjetividade (GIPNALS) junto ao Programa de Pós-graduação em Educação da Universidade Federal de Pelotas (PPGE/UFPel). Assistente Social e Coordenadora do Núcleo de Exensão e Pesquisa em Educação, Memória e Cultura (NEPEC) junto ao Campus Pelotas Visconde da Graça do Instituto Federal de Educação, Ciência e Tecnologia Sul-Rio-grandense (IFSul). Brasileira, residente em Rio Grande do Sul. Email: srangelita@hotmail.com

Doutora em Psicologia Social. Docente vinculada à Faculdade de Educação (FaE) da Universidade Federal de Pelotas e Coordenadora do Grupo Interdisciplinar de Pesquisa: Narrativas, Arte, Linguagem e Subjetividade (GIPNALS) junto ao Programa de Pós-graduação em Educação da Universidade Federal de Pelotas (PPGE/UFPel). Brasileira, residente em Rio Grande do Sul. Email: denisebussoletti@gmail.com 
também não tão distanciada que distorça e a transforme em uma outra coisa que ela não seja.

E esse é um risco que corremos, de não identificarmos mais a imagem, sendo ela uma outra coisa. E isso tem que ver com a perda da aura. Ou seja, há um resquício da aura que sempre permanece na imagem, ainda que ela esteja em declínio. E as imagens mecânicas, o que elas nos podem trazer? Podem trazer a possibilidade de sua leitura? Ou é uma linguagem estranha que nós já não mais falamos? Será que essas imagens são passíveis de serem lidas por nós?

Há um filme extraordinário que eu vi, Hausweg, de Farocki, um filme de 15 minutos. Ele diz respeito às imagens que são captadas por um robô. E isto é exatamente a questão da fronteira do olhar, do olhar humano, do que é reconhecível, do que não é reconhecível. Acho que isso é um paradoxo. Não é uma resposta, será sempre um paradoxo. E o filme é interessante por isso, as imagens são de um robô, mas a montagem é feita por um homem. Porque sem essa montagem, sem esse exercício do humano, nós não reconheceríamos aquelas imagens. Ou seja, elas não nos diriam nada. Elas não fariam sentido. Mas, de fato, na questão da imagem há algo onde devemos reconhecer uma ordem, uma organicidade, qualquer coisa que nos faça lembrar, naquilo que vemos. Que nos faça lembrar, ou que nos olhe, neste sentido.

Então, pensando no caso especifico do filme, foi possível construir ou montar "algo" mesmo a partir de imagens mecânicas?

Exatamente. As imagens do robô eram aleatórias, mas é um filme que é construído e montado por um realizador que é um homem. Isso questiona o Doutoranda em Educação e pesquisadora no Grupo Interdisciplinar de Pesquisa: Narrativas, Arte, Linguagem e Subjetividade (GIPNALS) junto ao Programa de Pós-graduação em Educação da Universidade Federal de Pelotas (PPGE/UFPel). Assistente Social e Coordenadora do Núcleo de Exensão e Pesquisa em Educação, Memória e Cultura (NEPEC) junto ao Campus Pelotas Visconde da Graça do Instituto Federal de Educação, Ciência e Tecnologia Sul-Rio-grandense (IFSul). Brasileira, residente em Rio Grande do Sul. Email: srangelita@hotmail.com

Doutora em Psicologia Social. Docente vinculada à Faculdade de Educação (FaE) da Universidade Federal de Pelotas e Coordenadora do Grupo Interdisciplinar de Pesquisa: Narrativas, Arte, Linguagem e Subjetividade (GIPNALS) junto ao Programa de Pós-graduação em Educação da Universidade Federal de Pelotas (PPGE/UFPel). Brasileira, residente em Rio Grande do Sul. Email: denisebussoletti@gmail.com 
limbo em que vivemos da extrema mecanização do real, mas ao mesmo tempo a possibilidade de ainda manter esse cunho humano. Há aí uma nostalgia. Há aí qualquer coisa como uma necessidade de ainda nos reconhecermos nas imagens. Ou seja, não são representação no sentido clássico, mas também não são completamente autônomas, nem tão distanciadas que rompam totalmente com o olhar humano. Ou que rasguem completamente com a ideia da representação. Creio que há um fio, há algo que nos liga. Agora, já não podemos pensar na imagem como representação, pois aí já estamos a cair no anacronismo...

Poderíamos nisso pensar a questão das fotografias de arquivos e acervos institucionais? Que teriam sido capturadas e preservadas como uma memória especificamente institucional, mas que podem permitir novas aberturas?

Como se fosse um instrumento, não é? Só que elas existem para serem reconhecidas. Elas não existem para existirem sozinhas. Elas exigem a leitura.

Tratar-se-ia então de um trabalho de elaboração na tensão das ausências presentes nas imagens?

Há um excesso nestas imagens, pois aquilo que consegues ver, o que consegues reconhecer não é aquilo que foi visto. Há sempre esta distância, não é? Há um mito que acredita que aquilo que fotografamos corresponde exatamente aquilo que é. Mas é um mito. Pois aquilo que foi fotografado por alguém, em uma época que não é a nossa, com ideias e em um contexto histórico que nada tem a ver com o nosso, e nos chega hoje. Mas, como isso Doutoranda em Educação e pesquisadora no Grupo Interdisciplinar de Pesquisa: Narrativas, Arte, Linguagem e Subjetividade (GIPNALS) junto ao Programa de Pós-graduação em Educação da Universidade Federal de Pelotas (PPGE/UFPel). Assistente Social e Coordenadora do Núcleo de Exensão e Pesquisa em Educação, Memória e Cultura (NEPEC) junto ao Campus Pelotas Visconde da Graça do Instituto Federal de Educação, Ciência e Tecnologia Sul-Rio-grandense (IFSul). Brasileira, residente em Rio Grande do Sul. Email: srangelita@hotmail.com

Doutora em Psicologia Social. Docente vinculada à Faculdade de Educação (FaE) da Universidade Federal de Pelotas e Coordenadora do Grupo Interdisciplinar de Pesquisa: Narrativas, Arte, Linguagem e Subjetividade (GIPNALS) junto ao Programa de Pós-graduação em Educação da Universidade Federal de Pelotas (PPGE/UFPel). Brasileira, residente em Rio Grande do Sul. Email: denisebussoletti@gmail.com 
pode ser lido? Há um excesso a que nós nunca teremos acesso. Há uma distância que não conseguirás alcançar. O que tens será sempre uma coisa parcial. Portanto, verás a imagem, mas não tudo aquilo que está envolvido na imagem. Pois esse excesso é algo a que nós nunca teremos acesso. É o enigma. Isso é uma condição da imagem. A imagem é um enigma. O próprio olhar sobre as coisas é sempre um acesso parcial. $O$ enigma permanece. $O$ enigma é esse excesso, porque ele transcende o nosso ponto de vista.

Citando mais uma vez Didi-Huberman, essa é então a "inelutável cisão que separa em nós aquilo que vemos e aquilo que nos olha"8?

Exatamente. Inelutável! Porque nós nunca poderemos captar, e portanto nunca poderemos chorar, nunca poderemos falar sobre aquilo que não vemos. Há aí uma perda sobre a qual nunca poderemos falar, porque nem sequer a vemos, não temos acesso a isso. A nossa condição também é essa, é a condição da necessidade do luto, que é a de falar sobre a perda. $E$ isso é um paradoxo da nossa própria experiência, ter um acesso sempre vedado. Mas pode-se perfeitamente partir desse paradoxo. Que é extremamente interessante, que é explorar esse paradoxo. Daquilo que escapa, tudo aquilo que se perde, mas que ao mesmo tempo é condição do nosso olhar. Pois estaremos sempre submetidos a essa perda, mas ao mesmo tempo estaremos sempre fascinados por ela.

E esse é o verdadeiro olhar alegórico. Que é portanto ter consciência que as coisas não estão lá, ou que há algo que lá está mas que tu não sabes o

\footnotetext{
${ }^{8}$ DIDI-HUBERMAN, 2010.
}

Doutoranda em Educação e pesquisadora no Grupo Interdisciplinar de Pesquisa: Narrativas, Arte, Linguagem e Subjetividade (GIPNALS) junto ao Programa de Pós-graduação em Educação da Universidade Federal de Pelotas (PPGE/UFPel). Assistente Social e Coordenadora do Núcleo de Exensão e Pesquisa em Educação, Memória e Cultura (NEPEC) junto ao Campus Pelotas Visconde da Graça do Instituto Federal de Educação, Ciência e Tecnologia Sul-Rio-grandense (IFSul). Brasileira, residente em Rio Grande do Sul. Email: srangelita@hotmail.com

Doutora em Psicologia Social. Docente vinculada à Faculdade de Educação (FaE) da Universidade Federal de Pelotas e Coordenadora do Grupo Interdisciplinar de Pesquisa: Narrativas, Arte, Linguagem e Subjetividade (GIPNALS) junto ao Programa de Pós-graduação em Educação da Universidade Federal de Pelotas (PPGE/UFPel). Brasileira, residente em Rio Grande do Sul. Email: denisebussoletti@gmail.com 
que é, mas não podes desistir de procurar isso e tentar resgatar o que não abarcas. $O$ olhar alegórico é então esse, o que sabe que algo se perdeu, mas ainda assim o quer encontrar e quer salvar.

\section{É isso a imagem dialética?}

É o que nela irrompe. A imagem dialética é a promessa, mas também não é um mito, é uma promessa. Mas é uma promessa que sabes que não vais alcançar, mas que também não podes deixar de perseguir. Como qualquer promessa que vais tentar cumprir, mas quanto mais elevada é essa promessa, maior será a dívida. E, portanto, só podes dar conta dessa dívida e tentar cumprir a promessa que é: "Não esquecer, não esquecer..."

\section{REFERÊNCIAS}

BENJAMIN, Walter. Suhrkamp taschenbuch wissenschaft. Gesammelte Schriften. Band I-1. Frankfurt am Main: Suhrkamp Verlag, 1991.

BENJAMIN, Walter. Passagens. Belo Horizonte: Editora da UFMG, 2006.

BENJAMIN, Walter. A obra de arte na época de sua reprodutibilidade técnica. Porto Alegre: Zouk, 2012.

BENJAMIN, Walter. Sobre o conceito de história. In: BENJAMIN, Walter. O anjo da história. 8ª Ed. Belo Horizonte: Autêntica, 2012b, p. 07-20.

BENJAMIN, Walter. Imagens do Pensamento. Sobre o Haxixe e outras drogas. Belo Horizonte: Autêntica, 2013.

Doutoranda em Educação e pesquisadora no Grupo Interdisciplinar de Pesquisa: Narrativas, Arte, Linguagem e Subjetividade (GIPNALS) junto ao Programa de Pós-graduação em Educação da Universidade Federal de Pelotas (PPGE/UFPel). Assistente Social e Coordenadora do Núcleo de Exensão e Pesquisa em Educação, Memória e Cultura (NEPEC) junto ao Campus Pelotas Visconde da Graça do Instituto Federal de Educação, Ciência e Tecnologia Sul-Rio-grandense (IFSul). Brasileira, residente em Rio Grande do Sul. Email: srangelita@hotmail.com

Doutora em Psicologia Social. Docente vinculada à Faculdade de Educação (FaE) da Universidade Federal de Pelotas e Coordenadora do Grupo Interdisciplinar de Pesquisa: Narrativas, Arte, Linguagem e Subjetividade (GIPNALS) junto ao Programa de Pós-graduação em Educação da Universidade Federal de Pelotas (PPGE/UFPel). Brasileira, residente em Rio Grande do Sul. Email: denisebussoletti@gmail.com 
BOLLE, Willi. Fisiognomia da Metrópole Moderna. 2ª Ed. São Paulo: Editora da

Universidade de São Paulo, 2000.

BUSSOLETTI, Denise Marcos. Fisiognomias: Walter Benjamin e a escrita da história através de imagens. Estudios Historicos - cdhrp- Año II - Noviembre 2010 - $\quad №$ № 5 Uruguay. Disponível em http://www.estudioshistoricos.org/edicion5/0509Fisiognomias.pdf, acessado em 30/07/2016.

CANTINHO, Maria João. Aby Warburg e Walter Benjamin: a legibilidade da memória.

Disponível

em file://C:/Users/Usuario/Downloads/Aby Warburg e Walter Benjamin A Legibi li.pdf, acessado em 30/07/2016.

DIDI-HUBERMAN, Georges. Images malgré tout. Paris: Minuit, 2003.

DIDI-HUBERMAN, Georges. La imagen mariposa. Barcelona: Mudito \& Co, 2007.

DIDI-HUBERMAN, Georges. O que vemos, 0 que nos olha. $2^{\mathrm{a}}$ Ed. São Paulo: Ed 34,

2010.

DIDI-HUBERMAN, Georges. Diante da Imagem. São Paulo: Ed 34, 2013.

DIDI-HUBERMAN, Georges. A imagem sobrevivente. História da arte e tempo

dos

fantasmas segundo Aby Warburg. Rio de Janeiro: Contraponto, 2013a.

DIDI-HUBERMAN, Georges. Diante do Tempo. História da arte e anacronismo

das imagens. Belo Horizonte: Editora UFMG, 2015.

MISAAC, Pierre. Passagem de Walter Benjamin. São Paulo: lluminuras, 1998.

Doutoranda em Educação e pesquisadora no Grupo Interdisciplinar de Pesquisa: Narrativas, Arte, Linguagem e Subjetividade (GIPNALS) junto ao Programa de Pós-graduação em Educação da Universidade Federal de Pelotas (PPGE/UFPel). Assistente Social e Coordenadora do Núcleo de Exensão e Pesquisa em Educação, Memória e Cultura (NEPEC) junto ao Campus Pelotas Visconde da Graça do Instituto Federal de Educação, Ciência e Tecnologia Sul-Rio-grandense (IFSul). Brasileira, residente em Rio Grande do Sul. Email: srangelita@hotmail.com

Doutora em Psicologia Social. Docente vinculada à Faculdade de Educação (FaE) da Universidade Federal de Pelotas e Coordenadora do Grupo Interdisciplinar de Pesquisa: Narrativas, Arte, Linguagem e Subjetividade (GIPNALS) junto ao Programa de Pós-graduação em Educação da Universidade Federal de Pelotas (PPGE/UFPel). Brasileira, residente em Rio Grande do Sul. Email: denisebussoletti@gmail.com 